\title{
MERGING CULTURES: Danish Integration of Academic Data Service into Traditional Archive System
}

by Per Nielsen ${ }^{1}$

Danish Data Archives

\begin{abstract}
:
The historical outline of the Danish Data Archives as an academic service facility is outlined. The reasoning underlying a recent and globally unique organizational affiliation of the DDA, viz. to the group of traditional archives, is presented; and the stages of the merging cultures process are outlined. The appropriateness of the archives integration is demonstrated in a presentation of projects that were not feasible in the old university affiliation of the DDA. An outlook towards future projects is also given

\section{Background and history of the DDA}

The Danish Data Archives (DDA) is slightly older than IASSIST. Founded in 1973, this author joined the DDA in 1974 - early enough to be there (in Toronto) when IASSIST was established as a "grass-roots organization" of individuals working in or using data archives, data centers, data libraries, or what these academic service facilities were named in each country or state. In the following, we shall refer to such installations as Data Organizations (DOs).
\end{abstract}

To some extent, IASSIST was set up as the response from the Old Boys' Network to the claim of the 1968-generation of more influence or power; to some extent IASSIST was set up to bridge the gap between the (predominantly male staffed and dominated) European Academic Data Archives and the (astonishingly female influenced) North American Data Libraries. IASSIST represented a merging of cultures according to generation, gender, and geography.

Be it as it may: IASSIST has survived with astonishingly small adjustments in a changing environment, borne by the enthusiasm and energetic work of (especially North American) individuals. During the same period, many DOs have undergone substantial changes. This report provides an overview documentation of some of these changes in a small country (Denmark, 5.2 million inhabitants) and refers in the form of parallels to changes in a number of other countries, predominantly in Europe.

\subsection{Feasibility Project of the Danish SSRC 1973- 1976(1978)}

The DDA was established on April 1st, 1973, after several years of preparation within the Danish Social Science Research Council (SSRC), as a feasibility project dealing with archiving and servicing problems related to three major data types:

\begin{abstract}
1.1.1. Political and Social Survey Data, i.e. questionnaire-collected research data resources in a de facto anonymous form. This was the "typical DO activity", known from e.g. the ICPSR, the Zentralarchiv, and the ESRC Data Archive.
\end{abstract}

1.1.2. Economic Time Series and to some extent regional data, both in terms of contents and methods (harmonization, adjustments to regional changes, etc.) and computer handling systems. This area, especially the regional data aspect, was known from Norway, where the NSD was started in 1971.

1.1.3. Population Register Data, i.e. identifiable data on individuals. There were no known DOs active in this area, but it was expected to be central in the future.

Needless to say, it was the advent of the computer and the challenges inherent with its use that was the rationale behind the project. During the Feasibility Project Period (19731976), the staff (predominantly engineers!) were occupied with all the technicalities of the computer age; there was, unfortunately, less knowledge (or even ignorance) vis-a-vis the substantive issues within the research disciplines potentially contributing data to and using data from the project.

It is symptomatic for the situation that a Steering Committee consisting of former researchers, now research administrators (viz. the SSRC chairman, an organization professor from a Business School; the Director of the Danish National Institute of Social Research (ISR), a government research facility of considerable magnitude and influence; the Director of Danmarks Statistik (the Danish Central Statistical Office, CSO); and the Director of the National Archives (also heading the Provincial Archives) would establish the project with almost exclusively engineers as staff members. It illustrates the attitude that the computer age was still so young that only technical specialists were able to deal with the matter. Technicians were the priesthood of the time.

When the author of this article (an economist by training, but rather a sociologist by practice) was accepted as a staff member (February 1st, 1974), he was the first non-engineer in full-time employment as an academic staff member within areas 1.1.1 and 1.1.3 above (there were economists in 1.1.2, 
which lived its own life); only one half-time student had a social science training. Many years were to pass until the technical education and skills were considered the "side product" and the social science background was the focus of the staff qualifications.

By the end of the three-year feasibility project, the first "culture clash" emerged within the staff: The (few) social scientists felt that the (many) engineers were not appropriately contributing to the development of the organization and, especially, to its integration in the research milieus of the universities and other schools of higher education within the social sciences (broadly conceived). Already at this early stage did we (the economists) demand that all staff members reported their time spent on different (detailed) subprojects; of course, the time-use statistics calculated showed that there were too many engineers and a lack of social scientists if we were to fulfill the plans defined by the Steering Committee.

\subsection{Interim SSRC Period of Transition 1976-1978}

Given that the Danish SSRC (contrary to the situation in e.g. Norway and the UK, where the SSRCs finance the DOs to a great extent even to-day) had a formal limitation on the period of time in which the Council was allowed to run projects (three years), negotiations were carried out by the mid-seventies to find the lasting host of the DDA. Little by little, it was realized that a strong base in a social science research environment was more important than the technicalities; therefore, negotiations were carried out with the relatively large, public "midwife-institutions" (the ISR, the CSO, and the National Archives) to urge one of these established organizations to adopt the techno-baby. Given that not enough breeding monies were offered to keep the baby alive at its present size, the negotiations failed.

Internally, partly because the SSRC gradually shrinked the money sack and partly because the technicians ran projects according to their own interest rather than to the benefit of the baby (shown by the subproject time registration referred to above), a change in staff policy had to take place. More social science trained staff were employed when vacancies appeared (which they did frequently, because highly qualified computer people were in high demand everywhere); and, more importantly, the scope of the DDA was narrowed considerably: Both the Time Series Subproject and the Population Register Subproject (1.1.2 and 1.1.3 above) were abolished, and only the Survey Subproject (1.1.1) was kept in the final model.

Furthermore, the second "culture clash" emerged, this time involving external agents: The understanding and confidence between the DDA Director (an engineer) and the SSRC members (social scientists) deteriorated; and, in 1977, the directorship moved to the social science side when the former director returned to concentrate on his own private consultancy firm.
The final organizational belonging of the DDA ended up being decided by opportunistic political/bureaucratic considerations rather than substantive research concerns: The Ministry of Research and Education (whose minister happened to come from and be elected MP in Odense!) found it relevant to support the smaller university centers rather than the big universities; consequently, Odense University was urged (it cost them money!) to take the baby into custody.

\subsection{Independent National Institute of Odense University 1978-1988(1992)}

Formally by April 1st, 1978 (five years after establishment), the DDA was moved to Odense; the physical move took place at the turn of the year 1978/79. Looking in the rearview mirror, this turned out to be the beginning of the consolidation decade, the happy childhood of the baby: After initial fightings over relative budget sizes, the DDA ended up in a stable and acceptable economic situation.

Organizationally, the DDA was set up with a double reference structure: On one side, as employees of the University, the DDA had to follow the rules of the Rector and Board of the University. On the other side, the DDA had an external Board of Overseers (five persons) who took care of the more narrow inspection of the activities and the development of the organization. In practice, to be honest, the DDA Director and the staff took most of the strategic decisions during this decade of consolidation; the baby was free to mature according to its own qualifications and cumulation of experience. More and more, the DDA staff identified with the "DO culture" (acquired and supported from international cooperation on many different levels and in many different projects) rather than anything else. (This is the kind of "data archive movement" culture that has kept IASSIST going strong for so many years.)

All was well; nobody questioned the relevance of the DO culture or the utility of the DDA activities, and most staff members considered the Odense University affiliation a permanent one. But alas! - The centre-right governments of the mid-eighties saw it as their major task to shrink the public sector, and the universities had reductions in their budgets at the same time as there was in increase in student enrolments. Universities had to critically inspect their resource allocation; and, needless to say, the eyes of the Odense University administration fell on the DDA during that process: The university demanded that the 3 academic staff members of the DDA (all with titles of associate professors) should participate in the normal social science curriculum of the university, teaching in the same amount of time as all other professors at the university.

The DDA staff argued that (1) formally, the DDA was an institute with national coverage, not an institute with special contribution to Odense University; (2) the teaching obligation of the academic staff was fulfilled in national 
training programs rather than in the Odense University curriculum; (3) the Ministry of Research and Education gave the budget of the DDA directly, exactly in order to make sure that the archive could fulfill its national obligations.

\subsection{Dispute Period and Review and Negotiation Process 1988-1992}

In fact, this was the fourth "culture clash", viz. between more and more strangled university administrators and DDA's relatively "anarchistic DO culture" (in the best sense of the term). When it turned out that the "stubborn rector and top administration" of the University were not willing to listen to the arguments of the DDA director and staff, we told them that we had to discuss the situation and our future with the DDA Board of Overseers. Of course it was annoying and frustrating for the university top management to see that their subordinates did not just obey orders (which they were supposed to do under the "visible management model" which was in fashion).

The DDA director and academic staff told the university administration that we would opt for a review process - if the DDA Board was in agreement. Fortunately, the Board Members were in agreement; they were even enthusiastic about such a step, because the Evaluation or Review Mania had floated over the country as a politically correct measure in the years of budget cutting

A review committee of six established researchers was set up (nominated by three research councils - social science, humanities, and medicine - and three important research institutions). The review committee report was generally favourable seen from the viewpoint of the DDA Board and staff; they presented a number of recommendations among which the organizational ones are of interest in this context:

The uncertain leadership structure should be abolished; it had been inadequate right from the outset and was critical in times of crisis.

The DDA should be relocated institutionally, and six possible solutions to the organizational setting were proposed for the DDA Board to further negotiate. (Odense University was not among the institutions recommended; they had been so negative in the review process that they disqualified themselves in the eyes of the review committee.)

After discussions with the involved research councils (for social science, humanities, and medicine) and the major research milieus within the same disciplines the Board could start negotiating a final placement for the DDA, now an adolescent. There were three organizational belongings that were considered interesting, viz.:

1.4.1. The DDA as a unit within the Danish CSO
(Danmarks Statistik). It took only one meeting to be turned down: The Director of the CSO held that the two cultures could not be merged, especially due to two incompatible phenomena: (1) Where the DDA had always tried to push their (anonymized) data on as many users as possible, the CSO had the principle of keeping their (identifiable) data strictly within the organization itself. (2) Where the DDA had always succeeded in keeping their services free of charge, the CSO tried to earn a big fraction of their total budget by user payments. [Needless to say, the DDA interest in a CSO placement was exactly to change that big organization in a more service-oriented direction.]

1.4.2. The DDA as a unit within the Danish Computer Center for Research and Higher Education $(\mathrm{UNI} * \mathrm{C})$. The UNI*C Director was interested; she felt that the center should add substance to its predominantly technical services, and they were under transformation so that the integration would be feasible at short notice. The DDA could choose between Copenhagen and Aarhus if they were to go for that model. The transaction was bureaucratically simple, because the DDA would stay within the realm of the same government department, viz. the Ministry of Research and Education.

1.4.3. The DDA as a unit within the National Archives. Here again, the DDA Board was met with relatively open arms (i.a. because the outgoing Director of the Danish National Archives had been functioning two periods (6 years) on the DDA Board during the mid-eighties). The DDA could stay in Odense, because the archives were spread over the country anyway. The transaction was bureaucratically more complicated, because the DDA would have to change government department, moving from the Ministry of Research and Education to the Department of Culture. There was an incalculable risk of losing money during such a transfer.

All in all, we were quite satisfied with the negotiations. Getting a "yes" in two out of three proposals is not all that bad! - Several rounds of negotiations were carried out with the management of the two possible hosts; I think it is fair to simplify the matters to the following decisive elements that destinguished the two:

Continuity: Because the DDA could continue its activity in Odense in the National Archive-model, there was no risk of loss of professional capacity in that model. There was a risk of losing substantial parts of the "DO culture" in a geographical move and thus a risk of assimilation with the new culture 
(maybe even annihilation of the "DO culture") rather than integration into the new culture with DDA's own cultural identity relatively intact.

Permanence: The National Archives, being several hundred years old already, and being one of the only institutions mentioned in the Constitution, will survive new centuries. UNI*C, on the other hand, was already undergoing severe changes in business plans - in transition from being predominantly a mainframe host to having a wider agenda: Mainframe host (parallel processors and other very expensive equipment), facility management host, network administrator, and value added services agent.

Substance: The major argument, however, was that the substance dealt with in the traditional archives and in the DDA was the same: Both are information agents, the major difference being the data-carrier - which will change in the traditional archives anyhow. Many avenues of DDA development were more easily passable in the National Archives model than in the UNI*C model.

The choice having been made, only the bureaucratic work remained; and even though this process took considerably longer time than expected it ended succesfully: As of January 1st, 1993, the DDA was a unit in what had, in the newly enacted Archives Act, been named the Danish State Archives (SA). We could thank our Board Members (whose assignment period had twice been prolonged with one year because the transition took so long to carry through), and we were cast in the arms of a new host

\subsection{Independent Unit in the Danish State Archives Group from 1993}

The "anarchistic DO culture" had to be integrated into the "bureacratic civil servant culture" according to the decisions taken. As always when you move in with new people, there was some reluctance and cautiousness from both sides: From the DDA point of view, we insisted on staying separate for some time to secure (reassure) the independence; we were not going to be "swallowed" by this, as we considered, somewhat "dusty" system ten times larger than we were.

The entry avenue was paved with a number of lucky circumstances: (1) A new Director of the National Archives entered the arena a couple of years before us, and he came from the university and research circles, too; (2) yet another unit had been adopted in the State Archives only three months before us; (3) a modernization process had been started within the archives themselves. Partly due to these circumstances, the entry into the New World (which is a very Old World!) was succesful and seems to develop to the benefit of both sides. Before looking into that, however, we shall make a short digression to a description of our new "family" and then return to a specification of the potentials of the new affiliation of the DDA.

\section{Short Description of the Danish State Archives}

Before the advent of the Archives Act of 1992, the State Archives were referred to as "The National Archives and the Provincial Archives" - most of which were century-old. In the Archives Act of 1992, the State Archives (SA) was defined as a group; we shall very briefly introduce these institutions and the rest of the archives complex in the country.

The Danish State Archives have less than 200 man-years at their disposal; quite a considerable number of the employees, furthermore, are not regular employees; rather, they are unemployed or disabled persons undergoing training or rehabilitation programs on behalf of social authorities.

The staff-size og the Danish State Archives in comparison with the size of the state administration that they serve is considerably lower than in the other Nordic countries, a fact which has been demonstrated to the politicians again and again.

\subsection{The National Archives}

The National Archives (Rigsarkivet) and its predecessors (i.a. Geheimearkivet, the Secret Archives) date back some 400 years. The institution is located face-to-face with the Danish Parliament (Folketinget). With approx. 80 man-years available, the National Archives is obliged to make an appraisal of all documentary material in central government and archive what is deemed necessary from legality considerations and to document the present for future researchers.

The National Archives is divided into an Appraisal Branch (incl. a private archives unit, a military archives unit, and an MRDA unit) and a Servicing Branch; also, the institution hosts the Secretariat of the whole group of the Danish State Archives.

\subsection{The Provincial Archives}

There are four Provincial Archives. Their purpose is to provide archival facilities for government agencies spread over the country. Also, voluntarily, the county and municipality administrations may deposit their archives with the provincial archives; however, they have to pay. Even so, they have to abide by the principles for appraisal defined by the State Archives (formally: The Director of the National Archives).

Three of the Provincial Archives (for Zealand and the other islands east of the Great Belt, in Copenhagen; for the island of Funen in Odense; and for Northern Jutland in Viborg) are exactly 100 years old here in the mid-nineties. The fourth Provincial Archives, that of Southern Jutland in Aabenraa, is only about 60 years old. It was established some years after 
the Referendum in 1920 which brought Southern Jutland back under the Danish Crown; it cooperates closely with archives in Schleswig which remained German as an outcome of the Referendum.

Two Provincial Archives (in Copenhagen and Viborg) are "big" (approx. 35 man-years), two others (in Aabenraa and Odense) are small (approx. 10 man-years).

\subsection{The Danish National Business History Archives}

Founded as an independent state-financed institution in the fifties, the Danish National Business History Archives tries to reflect all aspects of business life: It holds archives from firms and business units as well as from organizations (employers' organizations, employee's organizations, private organizations and associations) as well as from individuals with a certain standing.

Needless to say, before as well as after the entry of the Danish National Business History Archives into the State Archives Group (entry per October 1st, 1992), there has been a need to define the functional dividing lines between that institution and the private unit within the National Archives.

Opposite the major volume within the National Archives and the Provincial Archives, the Danish National Business History Archives has to rely exclusively on voluntary depositing of material (much like the DDA); they have no legal claim that donors shall archive their administrative remains.

The Danish National Business History Archives has less than 15 man-years at its disposal; within that frame, it also serves as a municipality archive for the city of Aarhus where it is situated.

\subsection{The Danish Data Archives}

The DDA entered the "family" on January 1st of 1993; it had about 10 man-years of staff-time at its disposal in the operating budget when entering. Due to the uncertainties regarding affiliation in the late eighties and early nineties, it had become extremely difficult to attract research grants to augment the total level of activity.

Needless to say, there are donors of computer archives that may either deposit at the National Archives (MRDF unit) or at the DDA; we shall refer to the "functional integration" in some detail below.

2.5. Other Archive Groups (not in the Danish State Archives) Outside the "family", a number of archive institutions are of interest in terms of collaborative projects (private archival material) as well as because they rely on the definitions of the SA in terms of appraisal (City and Local Archives). The major groups are:

\subsubsection{The National Library: As per tradition,}

many private papers (especially from writers, artists and other actors in the cultural realm) end up in the National Library (next nabour to the National Archives in Copenhagen).

\subsubsection{The Labour Movement's Library and} Archives: Financed by the Labour Unions, this Library and Archive documents the labour movement in Denmark and is thus also predominantly in the private archives sector.

\subsubsection{The City and LocalArchives: According to the Archives Act of 1992, counties and municipalities have an obligation to keep their records according to the decisions taken by the Director of the Danish National Archives; however, they do not have to deposit the records with the Provincial Archives. More than a dozen of big city municipalities have established City Archives with a professionally trained archivist (usually a historian) as the head. In many minor municipalities, the Local Archives have been staffed only with amateurs in the past. From the Archives Act of 1992, however, Local Archives have to be part of the Municipality Administration and professionally managed; otherwise, the records shall be deposited with the Provincial Archives of the relevant region (paid for by the municipality).}

3. Advantages and Disadvantages of Archives Integration From the national viewpoint, the Archives Act of 1992 explicitly regulated that all public authorities shall deposit their archives in a "professional" archive institution. This is, of course, an important step in the direction of securing future historical research at all levels, the national, regional, and local.

In this section, however, we shall return from the digressional "family description" and look at the advantages and disadvantages of the integration of the Academic Service Facility (the DDA) into the Traditional Archive System (the $\mathrm{SA}$ ). Without doubt, the viewing angle is that of the DDA due to the fact that the author is placed there, and because that is the "natural" IASSIST platform for evaluation.

\subsection{The "Laissez-faire Period"}

As already touched upon above, the first year or so in the new family was characterized by a "laissez-faire" state of affairs in the sense that all parts did what they used to do without much interference. It was a period of gradual confidence-building. However, the period was also one where the activities of all units in the SA were thoroughfully documented in a 3-volume Action Plan.

When the DDA entered the SA, they were in the middle of this documentation process; so they could immediately add the DDA resources, products, and services to those of the 
other SA-units so that the final report presented to the Ministry of Culture provided an overview of the whole new group of the Danish State Archives.

Based on the SA Action Plan 1994-1998 that was published in three volumes by the end of 1993, a so-called Performance Contract was undersigned between the Ministry of Culture and the SA in 1994. The idea is that the archives get more resources (approx. 10 man-years) in return for specified improvements in performance (efficiency, servicemindedness, productivity). The first Performance Contract is running in the period 1995-1996, only; however, it is anticipated that a new contract be designed for the period 1997 through 2000 by the end of 1996.

During the "laissez-faire period" there were not many advantages or disadvantages of the new host situation. Life went on pretty much as in the past; the DDA was left with the same resources and the same tasks as under Odense University. However, on the positive side, this generated confidence that the SA system was not going to "swallow" the DDA; on the negative side, some resources had to be spent on statistical reporting and planning activities that were not immediately to the benefit of the DDA and our "traditional" user clientele.

\subsection{The Integrationist Period}

Gradually, as the work with the Action Plan 1994-1998 proceeded, it became necessary to define what was labelled "functional integration" (in fact meaning specialization) within the SA Group. In short, this means that, opposite to the century-old tradition, not all units can upkeep all the specialties of the archival business.

For instance, all the production and distribution of microfilm and micro-fiche will take place at one "virtual unit" (which happens to be located within one physical unit, viz. the Provincial Archives in Viborg). Similarly, the conservation activities are being collected in another "virtual unit", in this case spread over 2-3 physical units. Furthermore, we work with the notion of "specialist archives/archivists", meaning that one unit (and one archivist within that unit) is the SA specialist vis-a-vis one type of authorities (e.g. police authorities, county archives, hospital patients' files).

Turning to the MRDF material, there are two centers in the SA system: The DDA takes care of everything from the "private sector" (incl. research). Also, the DDA is responsible for research remains from many public authorities (e.g. the ISR and an institute for clinical epidemiology) and for a number of semi-public institutions (e.g. the Cancer Register, which is now being moved from the de jure private Danish Cancer Society to the public realm).

It took tough negotiations to define these functional division lines between the DDA and the MRDF unit of the National Archives. A fifth "culture clash" appeared between DDA's service-oriented activity, international orientation, and informal contact methods on one side and the MRDF-unit's acquisition-oriented activity, relative isolation, and formal contact methods. Furthermore, the MRDF unit of the National Archives was stuck with very old equipment whereas the DDA has been trying to be at the technical frontline.

So what's the difference, the sceptic might ask; hasn't the DDA held the Danish Omnibus Surveys, the Danish Welfare Studies, the Danish Time Budget Data, and other material from the Danish ISR all the time?

Yes! - But there is a difference, and the difference is twosided: Firstly, the DDA now holds not only survey materials that are de facto anonymous as before; the DDA can now hold materials that are registers according to the Danish Acts on Public and Private Registers. Secondly, with respect to public authorities, the DDA is not dependent on the willingness of the agent to understand the importance of archiving; if the Director of the National Archives and the Director of the Data Surveillance Authority agree that a register shall be archived, the DDA staff can collect that register from the data owner in a capacity as an archive authority.

Even in terms of research registers (especially medical registers) there was some reluctance to give very sensitive patient information to an archive that was a university institute. Being part of the "official archive system" improves the chances that single researchers and research groups are willing to deposit their materials. As a consequence, more data materials will be available from the DDA for future research under the new model.

The advantage for the DDA (or rather for our traditional user clientele) is that more research relevant information will be available for secondary analysis. The disadvantage, seen through the glasses of the DDA staff, is that more tasks are placed on our shoulders without a corresponding inflow of personnel resources. Furthermore, the DDA senior staff is heavily involved in tasks (appraisal of computerized stuff from public authorities that are not immediately of interest for our research users; modernization of the other units in the technical sense, incl. establishment of a new version of "their" archives data base on a new platform) that make life busier without augmenting the service level towards our primary users.

\subsection{The Immediate Future}

Like in many other countries, the politicians and the broader public are very interested in the so-called "information society". In Denmark, a Government Committee Report ("The Information Society in the Year 2000" was published in the autumn of 1994. It was immediately followed by the 
establishment of a separate Ministry of Research under which the national IT-strategy was located (in accordance with the recommendations in the Bangemann Report from the European Commission which appeared a few months earlier than the Danish Info-2000 Report). So, in March of 1995, the Government produced its annual IT-plan "From Vision towards Action: The Information Society in the Year 2000", which in some respects looks like the Clinton/Gore initiative in the direction of Information Superhighways, in other respects is encompassing a lot more due to the special character of the Danish society.

The Government IT-Plan for 1995 and the SA Performance Contract with the Ministry of Culture require a lot of decisions from the SA. Just to mention a single challenge with a long-range perspective: Before mid-1995, the SA is going to define the rules and procedures that we deem necessary in order to allow the authorities to adopt the practice of "the paper-less office" from the beginning of 1996 (paper-less, because incoming paper-mail is scanned and saved (e.g. in a TIFF-format or equivalent), and where in-coming e-mail as well as outgoing mail of all types are saved in searchable format, e.g. in the SGML-format - with a well-defined DTD - or in other expectedly long-term viable formats).

\subsection{The Longterm Perspective}

The advantage for the DDA of the placing within the State Archives system is, of course, that we "archived the institution" within a long-term viable institutional structure, forming part of the national information strategy. As many IASSISTers will realize (more or less horrified!), the whole raison d', itre of many data libraries may vanish within a very foreseeable future due to the fact that end-users can download their research resources directly from the producers or other facilitators - on a global scale.

In the near future, academic data service organizations will face a strong competition from private and quasi-public vendors trying to monopolize their services not unlike the way that many (European) CSOs have done in the past. The information society involves rapid institutional changes even to the information specialists.

To establish a condition with Freedom of Information (and equal access) is no longer a question of some academic institution-building, only. National, and in turn international (in Europe e.g. within the European Union) information strategies will be developed from the political level, and they will severely influence the survival conditions for most of our academic service institutions.

\section{Projects Facilitated by Archives Integration}

The functional integration of the academic data service and the traditional archive system has already had an impact on the "palette" of activities of the DDA. Below, we shall touch upon a few projects that are facilitated by this integration.

\subsection{The Source Entry Project}

Like the other Scandinavian countries, Denmark has excellent demographic sources. In order to ease the access to those sources that may account for so much as $80 \%$ of the use of traditional archival material, the traditional archives have had large projects (in part jointly with the Mormon church) producing films and fiches with these sources. The film/fiche versions of the sources have in turn been distributed to City and Local Archives, thus releasing the increasing pressure on the SA reading rooms.

It goes without saying that such demographic sources invite computerized treatment. And, indeed, many amateur historians and genealogists (organizationally cooperating within the association DIS-Danmark) have been entering a lot of these sources into computer programs. These source entry initiatives, however, were scattered in coverage, differing in quality, and more often than not non-transferable because of technical limitations.

In 1992, DIS-Danmark formed a Cooperation Committee for Source Entries (Danish acronym: SAKI), and several staff members from the Danish State Archives (incl. Hans Hans $\mathrm{J}^{-}$rgen Marker from the DDA) were invited to serve on that Committee. During less than one year's work (1992-1993), this Committee completed a set of recommendations (called the SAKI Model) for the creation of machine readable source editions of structured sources (published in a special issue of the DDA quarterly newsletter $D D A-N y \mathrm{t}$ ). The recommendations should secure higher quality of the products from this huge amateur project.

In order to improve the transferability of data, a special Source Entry Program (KIP) is offered to people who want to serve as source entry personnel. Furthermore, the DDA serves as the central archiving facility and distributing service for all these computerized sources. Finally, a Coordination Committee (KOKI) keeps track on who is doing what to avoid duplication of effort.

At the DDA, the computerized sources are standardized and documented. And the DDA can supply copies of sources (usually in paper-form, but if needed also on film or microfiche) free of charge to people who are willing to and capable of making contributions to the program. By the end of April, 1995, more than 5.1\% of the 1845 Census is available, with the 1787 Census in second place (3.4\%).

In a not too distant future, such frequently used demographic source material as censuses and church registers may be available in data form as well as in the form of scanned images (based on the film/fiche versions). This will revolutionize the nature of use of such sources and open a lot of new projects: Person recognition and family reconstitution based on neural networks; automatic movements up and down family trees in a graphically based environment; etc. 


\subsection{The Computerization "Rightsizing"}

As mentioned above, the "old SA-family" used technical equipment from the mid-eighties (mini-computer technology from Norsk Data); the system is completely closed from the outside world, because this was considered necessary to secure confidentiality at the time of installation.

In August-September 1995, all units within the SA (except the DDA which will be on that platform already) get new client-server equipment after specifications laid down in a group where the DDA has held the chairmanship. This means that the SA-units will be able to benefit from the resources on Internet and other communication networks, and it implies that a strategy can be adopted where the descriptions of the materials in the archives can be brought to the users electronically.

DDA is heavily engaged in a rescue operation where an existing (hierarchically organized) archival data base is going to be transferred to the client-server environment and entered into a relational data base system (viz. MS NT SQL Server).

Although these technical cooperation projects have drained resources from the DDA, they do hold a perspective for the future: Because the DDA has a longstanding experience with user contacts (the MRDF unit in the National Archives has only served about a dozen users since its inception in the early seventies; the DDA has several hundred user requests a year), we may well be disigning the user interfaces for the whole SA "family" in the future.

\subsection{The Register Research Facilitation}

As an initiative of the Danish Research Foundation, a Working Committee (where the author of this article was a member) has been defining a model that might facilitate the use of personal registers (incl. registers in the CSO) for research purposes. The recommendations of the Committee, to establish a Register Research Center, adjacent to but independent of the CSO, and to establish a Register Archival Facility at the DDA) are being implemented right now.

The DDA could not have played an active rÙle in this project without having an authorization to hold identifiable personal records. The idea is, furthermore, to take on a medically trained staff person to make sure that the many registers in hospitals and medical departments be rescued, to the benefit of contemporary and future research.

To people outside Scandinavia a comment may be relevant: The Danish society is administered almost completely via computer registers; the citizens are registered with the CPRnumber (Central Personal Number) as the unique identification code. This implies that all types of personal information may be merged in research projects, and this is of great importance - so far especially within medical research. This register-based research potential is considered to be unique for the Scandinavian countries.

\subsection{The Government System Contacts}

The placing of the DDA within the Danish State Archives seems to have brought us closer to the Government system than we were under Odense University. This implies that the DDA has been represented on numerous Committees and Working Groups where "the future is designed."

This being said, we still try to keep the "anarchistic DO culture" as our life-style and the equal access to information as our distribution principle. To do so is facilitated by a comment from the political system in the report leading to the Archives Act of 1992: The leading principle in the administration of the Archives Act is going to be to secure "the greatest possible openness."

\section{Closing Notes: Merging Cultures}

In less than a quarter of a century, a lot of "culture clashes" have been experienced by the DDA - internally and in the contacts with the outside world. My guestimate goes that we are now going to see a "reverse process" - a merging of cultures where there are not so many "computer-nicks" or research-discipline monopolists who claim their superiority. So much information will be readily available that technical and human network-building as well as inter-disciplinary sensibility, cooperation and understanding will be much more important than media-oriented or discipline-based exclusiveness.

In the Danish case, the merging cultures are visible in two respects already demonstrated in the project descriptions above: Firstly, from being a "traditional" social science data archive holding survey data relevant for the political and social sciences, the DDA is rapidly moving into a position where historians and medical researchers are added as new user groups. Secondly, since we had to abandon the Population Register Data subproject (cf. 1.1.3 on p. 3) in the mid-seventies, the activities have not included register data. There is no crucial difference in method analysing survey or register data; the two should complement each other rather than being seen as two different approaches. More often than not, register research projects will contain a process where subpopulation data held by the researcher have to be merged with register data held by some public authority; therefore, it seems logical to have the services and the data resources collected in one place - in a small country which cannot afford to have several, discipline-specific data service organizations.

On the Danish data arena, only the economic time series (incl. the regional data, cf. subproject 1.1.2 above) are not yet incorporated in the service "palette" of the data service unit; and, to be honest, I think that they should not be! Time series data should be available from the main producers, viz. the CSOs. Needless to say, they will be entered into the archives for historical research in due time; 
but as far as contemporary research is concerned, the time series data should be distributed by the producers - and if they introduce obstacles, we should concentrate our energy on removing these.

The major reason why I find that contemporary (economic) time series and regional data are unappropriate in academic DOs is that they are constantly changing - in the course of time (new weekly/monthly/quarterly/annual figures should be added) and because of changes in administrative regions (which necessitates a backward harmonization).

In conclusion: The technological development will have a crucial effect also on the institutional landscape a decade from now. We already face the rapidly changing conditions of our activity brought about by the Internet and WWW services; so far, we (the DO personnel) can feel easy at the frontier because we know more about these advanced technical information interchange facilities than most of our users. But take care: New generations of users are entering the professional scene; they know "the computer age" because they already grew up in it, and they will ask for services in terms of selective information facilitation that we are not yet able to produce.

There are plenty of challenges for IASSISTers for the next couple of decades. After that, many of the IASSIST pioneers can sit back in their homes, living on their pension schemes, communicating with each other about the rapid-changing world and the oddities of the younger generations.

The topics old people always communicated about ... - but we shall be in the favourable position to communicate electronically and globally!

1 Paper presented at IASSIST 21st Annual Conference May 9-12, 1995, Quebec City, Canada. 